\title{
Pectoral Nerve Block
}

National Cancer Institute

\section{Source}

National Cancer Institute. Pectoral Nerve Block. NCI Thesaurus. Code C154224.

A peripheral neural block of the medial and lateral pectoral nerves. 